\title{
Experimental Investigation of Cylindrical Thermal Energy Storage System using Bio-Based Phase Change Materials
}

\author{
Muath A. Alomair, Yazeed A. Alomair, Hussein A. Abdullah, Shohel Mahmud, Syeda Tasnim \\ School of Engineering, University of Guelph \\ 50 Stone Road East, Guelph, ON, N1G 2W1 Canada \\ stasnim@uoguelph.ca
}

\begin{abstract}
Thermal energy storage (TES) using phase change materials (PCMs) are an efficient and reliable technique to reduce consumption of energy. The heat transfer processes during phase change in PCMs is complex because of the simultaneous presence of solid and liquid phases where, solid and liquid fractions are continuously changing with time. The present experimental investigation focuses on the transient behaviour of the melting process and the dynamic of the solid-liquid interface in a cylindrical TES containing bio-based PCM. Coconut oil is used as a bio-based PCM and two different experimental conditions are investigated. The aim of this study is to improve the understanding of the fundamental of solid-liquid phase transition during melting, and a better characterization of the related heat transfer during phase change processes of bio-based PCM. To achieve these goals, an experimental setup is developed for the visualization of charging time, melt fraction location, and thermal field measurements.
\end{abstract}

Keywords: Phase change materials, Melting, Bio-based PCM, Experimental investigation

\section{Introduction}

Buildings use approximately $40 \%$ of the total energy consumed in USA followed by industry and transportation [1]. Approximately $\$ 370$ billion US dollar is spent each year to supply this energy and thus reduction in energy consumption is extremely important. One of the most efficient and reliable ways to reduce energy consumption is the use of PCMs in latent heat thermal energy storage (LHTES) system to store and release thermal energy. Several works have been done recently considering different types of PCMs and different heat exchanger geometries ([2-16]). The shell and finned tubes [6] and [7] is the only one tested on a prototype scale. A few works [8-10] also modelled shell and tubes heat exchanger as a sum of annular PCM storages to simplify the studies on the subject. Two concentric tubes constitute an annular PCM storage. The PCM fills the annular space and the heat transfer fluid circulates inside the inner tubes. Several authors further explored the heat transfer characteristics in annular tube heat exchangers experimentally $[8,11,12]$ and numerically [13, 14]. They found that especially during the charging period, natural convection plays a major role. Chiu and Martin [15] conducted an experimental study and validated their experimental results with numerical simulations without considering convection heat transfer and found very good agreement between the experimental and numerical results. This can be explained by the fact that heat transfer during melting and solidification processes in annular geometry is affected by different factors, such as, the PCM properties, thickness of the PCM, and on the injection configuration. Yao and Cherney [16] further reported that the effect of natural convection in an annular zone increases quickly with the size of the melted region.

There has been no study concerning phase change processes of bio-based PCM in cylindrical or annular geometry and this is the motivation of this study. Bio-based PCMs are made from renewable and underused feedstock, such as coconut oil, palm oil, and soybean oil. Bio-based PCMs are less flammable and cheaper than widely used paraffin and can be mass produced and this is the reason for selecting coconut oil (melting temperature $24^{\circ} \mathrm{C}$ ) a bio-based PCM in the present study. Cylindrical geometry is considered most promising for commercial heat exchangers, because of their high efficiency in a minimum volume [2] and this is the reason for selecting a cylindrical LHTES for the present investigation. 


\section{Experimental Work \\ 2.1. Experimental Setup}

An experimental setup is developed to carry out the experiments as shown in figure 1 with different components. The experimental setup consists of a test stand, cylindrical energy storage system, thermal regulator, K-type thermocouples, camera, NI data acquisition system, pump, flow meter, flow regulating valves, and a computer. The test stand accommodates a cylindrical TES system. The Plexiglas cylindrical energy storage system has a copper pipe located in the centre for bypassing heat transfer fluid (HTF). Water is used as a HTF. The cavity between the Plexiglas cylinder and the copper pipe is filled up with coconut oil PCM. The Plexiglas cylinder has $4.45 \mathrm{~cm}$ internal diameter and $8.96 \mathrm{~cm}$ height. The diameter of the copper pipe which is representing heater is $0.95 \mathrm{~cm}$. The Plexiglas cylinder has a thickness of 0.315 $\mathrm{cm}$. Two plastic pipes are installed on the top of the cylinder to allow expanding and shrinking the PCMs at atmospheric pressure. A Cole-Parmer Polystat thermal regulator is used to provide deionized water at a constant temperature to the cylindrical TES system through properly insulated plastic pipes. The water is continuously circulated by flow meter, flow regulating valve, and a built-in force/suction pump which has a maximum flow rate of $21 \mathrm{~L} / \mathrm{min}$. The water capacity of the pump is $2.8 \mathrm{~L}$. The Polystat thermal regulator has a temperature range of $5-80^{\circ} \mathrm{C}$, and it maintains the temperature to $\pm 0.1^{\circ} \mathrm{C}$. The thermal regulator requires $115 \mathrm{~V}$ and $250 \mathrm{~W}$ input power. To measure temperatures at different times, K-type

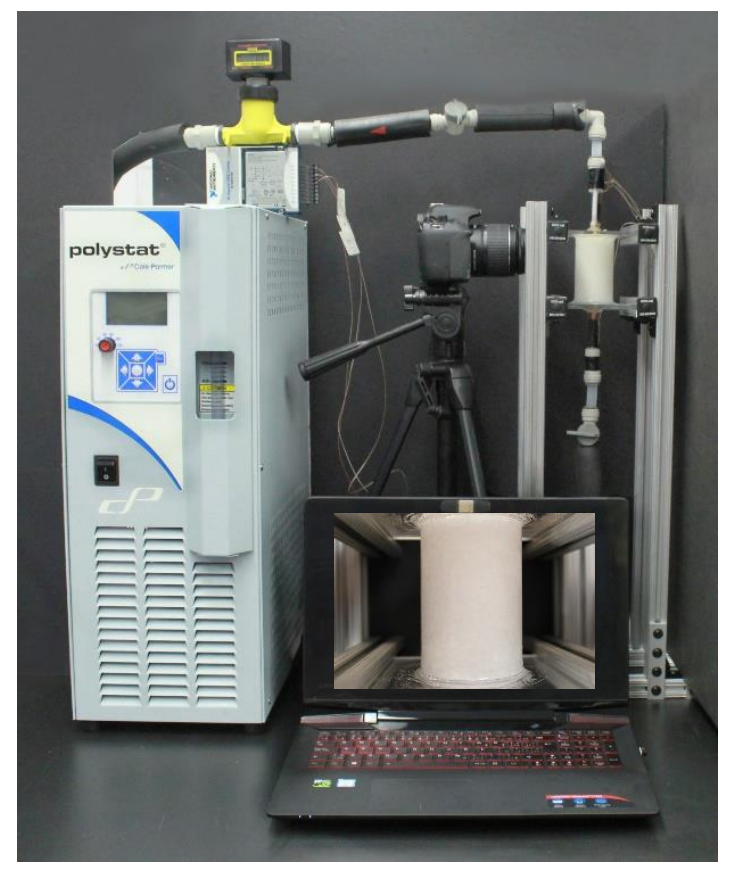

Fig. 1: Image of the experimental setup with the cylindrical TES system containing coconut oil.

$0.5 \mathrm{~mm}$ calibrated thermocouples $\left( \pm 0.1^{\circ} \mathrm{C}\right)$ are installed at different locations inside the cylindrical TES system and the water carrying pipes. A computer is used to record the thermal field data through a 16-Channel DAQ system which is connected to the thermocouples. A high definition Canon camera "EOS Rebel T2i model" is used to capture the images of the melting process periodically. Two different experimental conditions are selected for the present study as mentioned in table 1.

Table 1: Experimental operating conditions and dimensions of cylindrical TES system.

\begin{tabular}{|c|c|c|c|c|c|c|c|}
\hline $\begin{array}{c}\text { Exp } \\
\#\end{array}$ & PCM & $\begin{array}{c}\text { Initial temperature of } \\
\text { PCM }\end{array}$ & $\begin{array}{c}\text { Temperature of water in } \\
\text { heater }\end{array}$ & Height & Diameter & $\begin{array}{c}\text { Exp. } \\
\text { Duration }\end{array}$ & $\begin{array}{c}\text { Water flow } \\
\text { rate }\end{array}$ \\
\hline 1 & Coconut oil & $20^{\circ} \mathrm{C}$ & $34^{\circ} \mathrm{C}$ & $3.53 \mathrm{in}$ & $1.75 \mathrm{in}$ & $262 \mathrm{~min}$ & $5.9 \mathrm{~L} / \mathrm{min}$ \\
\hline 2 & Coconut oil & $5^{\circ} \mathrm{C}$ & $40^{\circ} \mathrm{C}$ & $3.53 \mathrm{in}$ & $1.75 \mathrm{in}$ & $40 \mathrm{~min}$ & $6.2 \mathrm{~L} / \mathrm{min}$ \\
\hline
\end{tabular}




\subsection{Experimental Procedures}

The PCM is poured using a pressure syringe into the cylindrical TES system. The PCM is poured by multiple steps through one of its vent to ensure no air trapped inside the enclosure. Next, the temperature of the deionized water inside the thermal regulator is raised to $34^{\circ} \mathrm{C}$ to initiate the melting process. During the melting process, the temperatures are recorded at every one second interval and images of the melting are captured at every one minute. The captured images and thermal field data obtained from the experimental work are summarized and discussed in the results and discussion section.

\section{Results and Discussion}

\subsection{Visualization of Melting Front}

Figure 2 (a) and figure 2 (b) show the images of melting for the two different cases along with the melting front location at different times. Figure 2 (a) represents case 1 when the initial temperature in the heater is $34^{\circ} \mathrm{C}$ and the $\mathrm{PCM}$ is in solid phase at $20^{\circ} \mathrm{C}$. As the PCM comes in contact with the heated pipe, the temperature of the PCM especially that are in contact with the heater increases (sensible heating) until the PCM reaches its melting temperature. Then the PCM surrounding the heater heats up (latent heating) absorbing thermal energy in terms of conduction heat. At the beginning of the melting process, conduction dominates the thermal energy transfer from the heater to the PCM as shown in figure 2 (a).

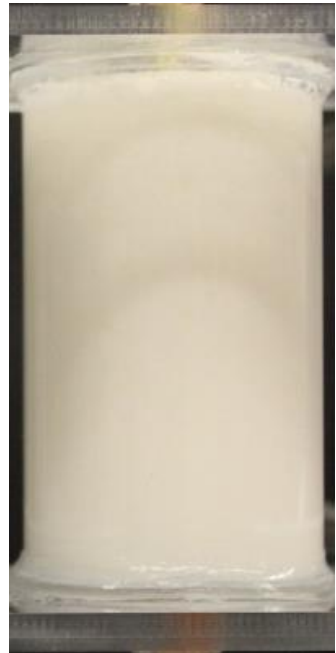

Time $=2 \min$

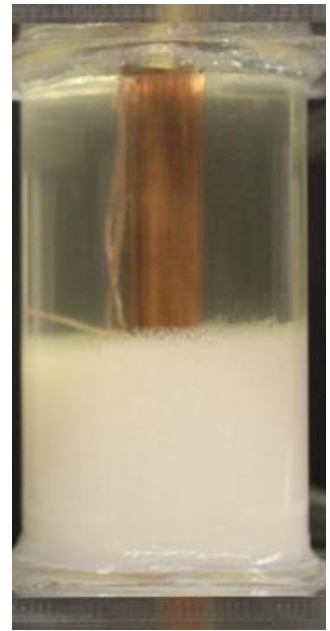

Time $=146 \mathrm{~min}$

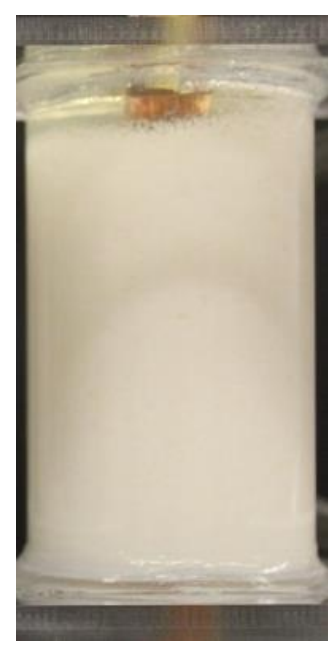

Time $=76 \mathrm{~min}$

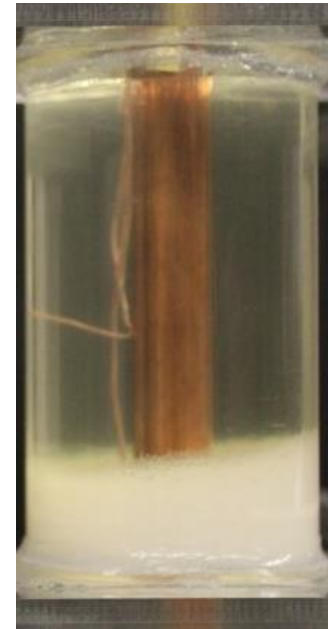

Time $=188 \mathrm{~min}$

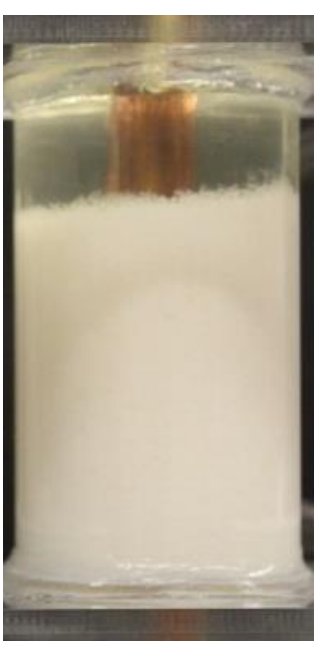

Time $=102 \mathrm{~min}$

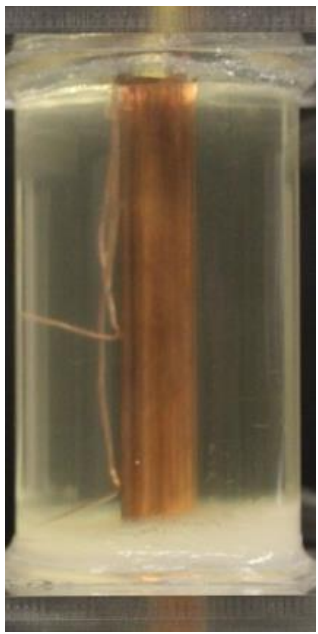

Time $=228 \min$

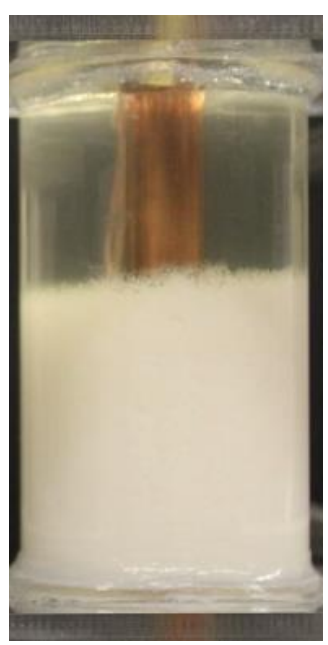

Time $=126 \mathrm{~min}$

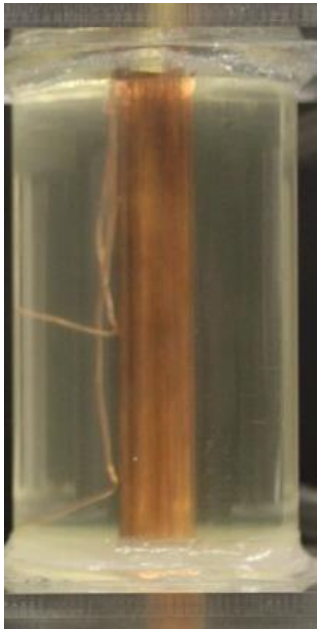

Time $=260 \mathrm{~min}$

Fig. 2 (a): Images of melting front at eight different times for case 1.

As the melting continues, the thickness of the liquid PCM increases, and a weak circulation of liquid PCM is observed indicating the presence of natural convection heat transfer along with conduction heat transfer. The effect of natural 
convection intensifies as the melting progresses with strong circulation of liquid PCM. Hot liquid PCM moves upward due to this anti-clockwise circulation, thus increasing the rate of radial melting at the top of the cylindrical TES along with the heating from the heater. Therefore, PCM located in the upper layer melts first and the melting front moves downward with the vessel shape. Figure 2 (b) represents case 2 when the initial temperature in the heater is $40^{\circ} \mathrm{C}$ and the PCM is in solid phase at $10^{\circ} \mathrm{C}$. Identical melting behaviour is observed for case 2 , but less melting time is required due to larger temperature difference between the heater and the PCM for case 2. almost at the melting temperature once melting is completed. In figure 3 (b), almost identical trend in thermal field measurement is observed as in figure 3 (a). But due to a higher temperature difference in case 2 between the PCM and the heater, the differences in slopes among the three temperatures at the

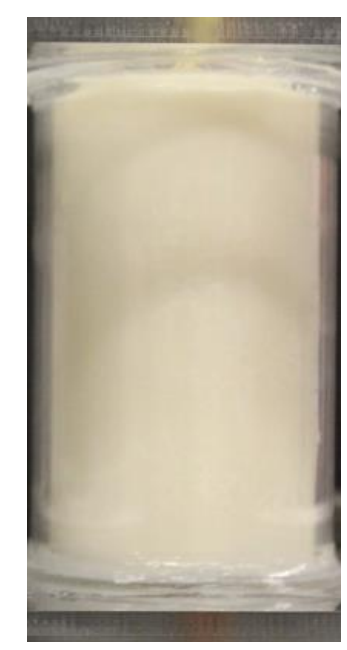

Time $=2 \min$

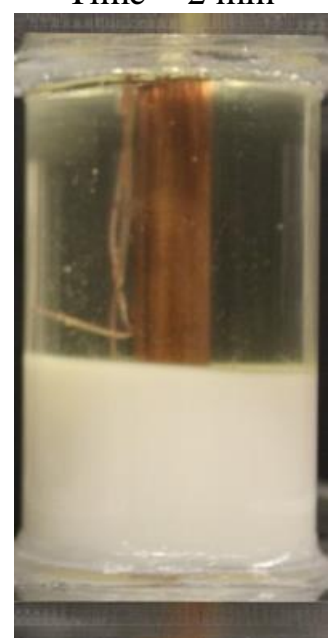

Time $=29 \min$

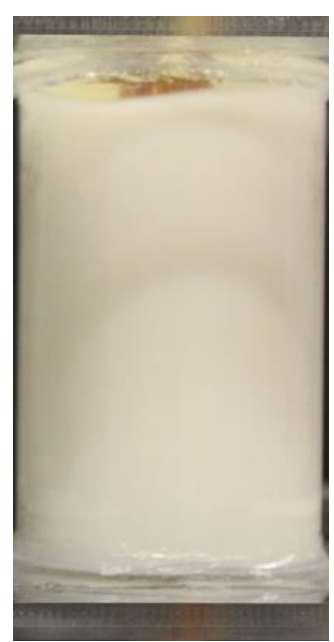

Time $=14 \min$

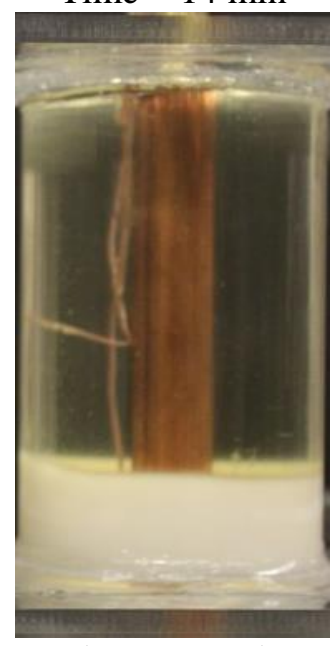

Time $=33 \mathrm{~min}$

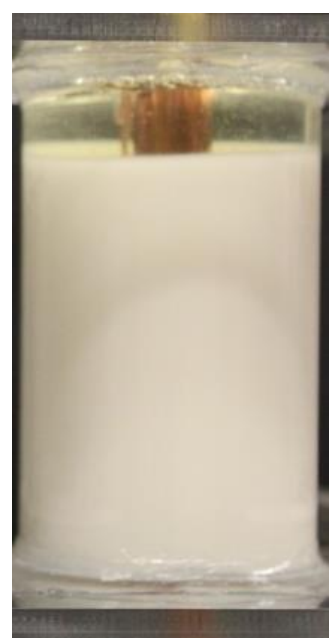

Time $=18 \min$

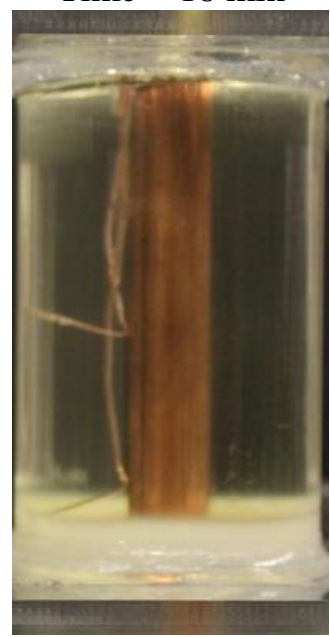

Time $=35 \mathrm{~min}$

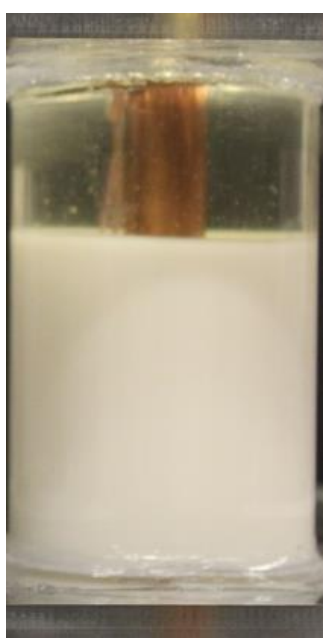

Time $=20 \mathrm{~min}$

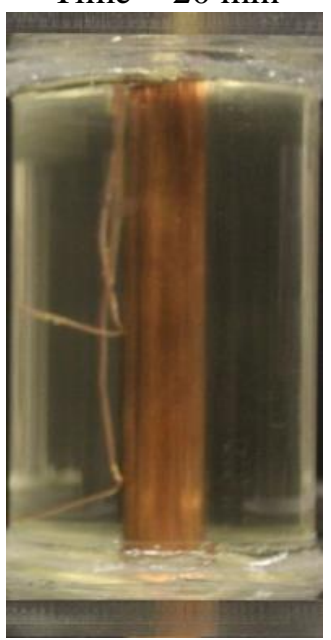

Time $=39 \mathrm{~min}$

Fig. 2 (b): Images of melting front at eight different times for case 2.

beginning of melting is less compared to case 1. But the temperature at the bottom exceeds the melting temperature once melting is completed since higher heater temperature for case 2. The effect of top or bottom injection does not have an impact on the melting for the selected height of the cylindrical TES system 


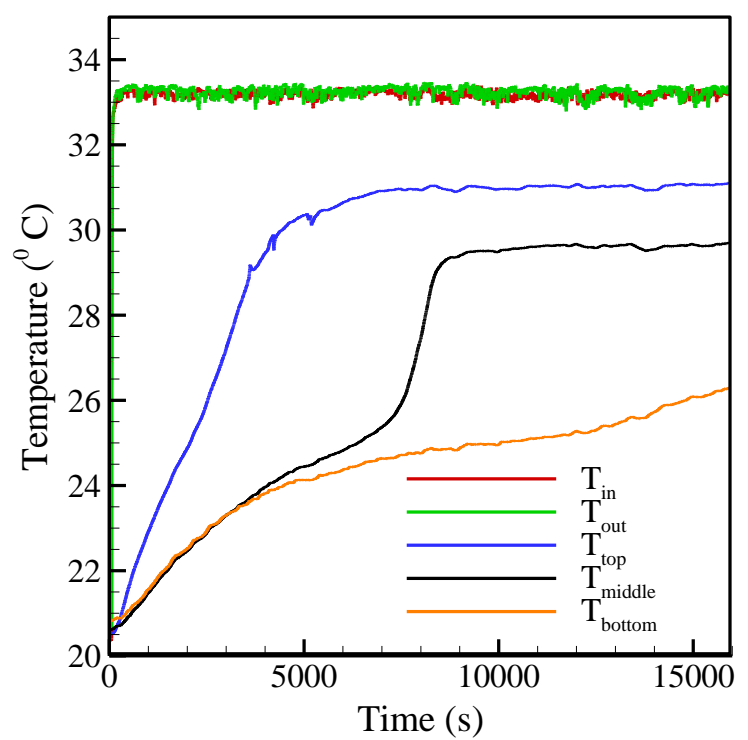

Fig. 3 (a): Evolution of temperatures at different locations in the TES system and the heater for case 1.

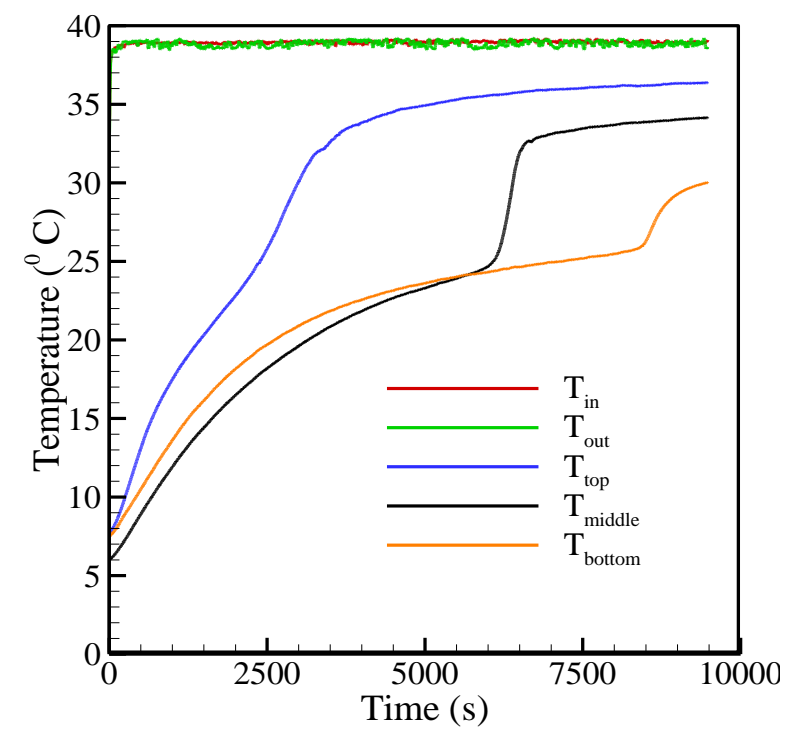

Fig. 3 (b): Evolution of temperatures at different locations in the TES system and the heater for Case 2.

In conclusion, a higher temperature difference between the PCM and the heater requires less time for melting and creates less temperature gradient in the axial direction compared to a less temperature gradient.

\section{Conclusion}

Thermal energy storage is an excellent method to preserve thermal energy. PCMs are becoming increasingly vital for many engineering applications because of environmental concerns and the rising cost of fossil fuels. PCMs can be used for many waste heat recovery applications, such as buildings envelopes and equipment, buildings space heating and cooling, refrigeration systems, solar collectors and electronic products. The present study aims to improve the understanding of the fundamental of solid-liquid phase transition during melting, and a better characterization of the related heat transfer. To achieve this goal, an experimental setup was built up for the visualization of melting, melt front location, and the measurement of thermal field. In future, nanoparticles will be added along with porous medium to enhance the heat transfer during phase change processes of PCMs. 


\section{References}

[1] US DOE Building windows and envelope R\&D-Retrofit focus on eco build, 2009.

[2] A. Sharma, V. V. Tyagi, C. R. Chen and D. Buddhi, "Review on thermal energy storage with phase change materials and applications," Renew. Sust. Ener. Rev., vol. 13, pp. 3183-3145, 2009.

[3] M. Jourabian, M. Farhadi and A.A.R. Darzi, "Outward melting of ice enhanced by $\mathrm{Cu}$ nanoparticles inside cylindrical horizontal annulus: Lattice Boltzmann approach,” Appl. Mathematical Model., vol. 37, pp. 8813-8825, 2013.

[4] N. S. Dhaidan, J. M. Khodadadi, T. A. Al-Hattab and S. M. Al-Mashat, "Experimental and numerical study of constrained melting of n-octadecane with $\mathrm{CuO}$ nanoparticle dispersions in a horizontal cylindrical capsule subjected to a constant heat flux," Int. J. Heat Mass Trans., vol. 67, pp. 523-534, 2013.

[5] S. H. Tasnim, R. Hossain, S. Mahmud and A. Dutta, "Convection effect on the melting process of nano-PCM inside porous enclosure,” Int. J. Heat Mass Trans., vol. 85, pp. 206-220, 2015.

[6] R. Bayón, E. Rojas, L. Valenzuela, E. Zarza, "Analysis of the experimental behaviour of a 100kWth latent heat storage system for direct steam generation in solar thermal power plants," Appl. Ther. Eng., vol. 30, no. 17-18, pp. 2643-2651, 2010.

[7] D. Laing, C. Bahl , T. Bauer, D. Lehman, W-D Steinmann, "Thermal energy storage for direct steam generation," in Proceedings of SolarPACES. Berlin, Germany; 2009.

[8] A.Trp, K. Lenic, B. Frankovic, "Analysis of the influence of operating conditions and geometric parameters on heat transfer in water-paraffin shell-and-tube latent thermal energy storage unit," App. Ther., Eng., vol. 26, pp. 1830$1839,2006$.

[9] K. A. R. Ismail, M. M. Abugderah, "Performance of a thermal storage system of the vertical tube type," Energy Convers. Manage., vol. 41, no. 2, pp. 1165-1190, 2000.

[10] M. Esen, T. Ayhan, "Development of a model compatible with solar assisted cylindrical energy storage tank and variation of stored energy with time for different phase change materials," Energy Convers. Manage., vol. 37, no. 12, pp. 1775-1785, 1996.

[11] F. Agyenim, P. Eames, M. Smyth, "Heat transfer enhancement in medium temperature thermal energy storage system using a multitube heat transfer array," Renew. Energy, vol. 35, no. 1, pp. 198-207, 2010.

[12] H. M. Ettouney, I. Alatiqi, M. Al-Sahali, M. A. Al-Ali, "Heat transfer enhancement by metal screens and metal spheres in phase change energy storage systems," Renew. Energy, vol. 29, pp. 841-860, 2004.

[13] O. Mesalhy, K. Lafdi, A. Elgafy, K. Bowman, "Numerical study for enhancing the thermal conductivity of phase change material (PCM) storage using high thermal conductivity porous matrix," Energy Convers. Manage., vol. 46, pp. 847-867, 2005.

[14] M. Costa, D. Buddhi, A. Oliva, "Numerical simulation of a latent heat thermal energy storage system with enhanced heat conduction," Energy Convers. Manage., vol. 39, no. 3-4, pp. 319-330, 1997.

[15] N. W. Chiu, V. Martin, "Submerged finned heat exchanger latent heat storage design and its experimental verification," Appl. Energy, vol. 93, pp. 507-516, 2012.

[16] L. S. Yao, W. Cherney, "Transient phase change around a horizontal cylinder," Int. J. Heat Mass Transf. vol. 24, no. 12, pp. 1971-1981. 